\title{
An evaluation of nursing documentation of acutely admitted older home-living medical patients in a Danish hospital
}

\author{
Ditte Maria Sivertsen*1, Helle Gybel Juul-Larsen ${ }^{1}$, Janne Petersen ${ }^{1,2}$, Louise Lawson-Smith ${ }^{1}$, Tove Lindhardt ${ }^{3}$, Ove \\ Andersen ${ }^{1,4}$ \\ ${ }^{1}$ Optimed, Clinical Research Centre, Amager Hvidovre Hospital, University of Copenhagen, Denmark \\ ${ }^{2}$ Section of Biostatistics, Department of Public Health, University of Copenhagen, Denmark \\ ${ }^{3}$ Department of Internal Medicine, Herlev Hospital, University of Copenhagen, Denmark \\ ${ }^{4}$ Emergency Department, Amager Hvidovre Hospital, University of Copenhagen, Denmark
}

Received: July 13, 2017

DOI: $10.5430 /$ cns.v6n1p20
Accepted: August 28, 2017

Online Published: October 23, 2017

URL: https://doi.org/10.5430/cns.v6n1p20

\begin{abstract}
Background: Documentation enhances patient safety and continuity. According to national Danish guidelines, nursing documentation should contain core areas such as: nutritional status, pain, sleep, urinary- and bowel elimination, skin and tissue, cognitive and psychosocial factors. Documentation practice and its association to patient impairments have not been examined as a comprehensive, combined set of nursing core areas in acutely admitted older medical patients. Therefor the objective of this study was to examine levels of nursing documentation and the associations between documentation levels and patient impairments.

Methods: A descriptive study of acutely admitted patients above 65 years old. Audit of handwritten nursing records and structured patient interviews were conducted to assess eight core areas based on the national Danish guidelines for nursing documentation: nutritional status, pain, sleep, urinary- and bowel elimination, skin and tissue, cognitive and psychosocial factors. Furthermore measures of Charlson Comorbidity Index (CCI) and self-reported health were collected.

Results: 90 acutely admitted medical patients $\geq 65$ years were enrolled. The prevalence of documentation was between 4 and $80 \%$. We found a higher prevalence of unstructured documentation. Looking at six of the eight core areas, $33 \%$ of the patients had 0-2 areas documented. For all the eight core areas we found no difference in the prevalence of documentation for patients with impairment compared to patients without impairment, nor did we find a significant association between patient documentation and age, sex, CCI, or self-rated health.

Conclusions: The results implies that something else than national guidelines, patient impairments, age, sex, CCI and self-rated health of the patient are determining whether documentation is done or not.
\end{abstract}

Key Words: Nursing documentation, Older medical patients, Structured documentation, Unstructured documentation, Nursing records

*Correspondence: Ditte Maria Sivertsen; Email: ditte.maria.sivertsen@regionh.dk; Address: Optimed, Clinical Research Centre, Amager Hvidovre Hospital, University of Copenhagen, Kettegaard Allé 30, 2650 Hvidovre, Denmark. 


\section{INTRODUCTION}

The health care sector is under constant development. High specialization, transfers between wards, shorter hospitalizations and cross-sectoral collaboration have increased the demand for systematic documentation and effective communication. To provide and coordinate coherent 24-hour nursing care the quality of the information available to the nurse is essential. ${ }^{[1-3]}$ Furthermore, documentation is necessary for patient safety and continuity. ${ }^{[3-5]}$ Even though documenting patient data has been a nursing task for more than 150 years, ${ }^{[6]}$ and the exchange of information is a significant nursing activity, ${ }^{[3]}$ documentation practices is still today an area of extensive challenges. ${ }^{[7-11]}$ Increased requirements for documentation and demands to fulfill quality standards are a part of everyday practice in Danish hospitals, as patient treatment and trajectories are getting more complex. Increased documentation can be seen as a management tool, which is linked to the governing ambitions within the New Public Management, a market inspired public administration model, striving to make public institutions such as health care more efficient and productive through policy defined production targets. ${ }^{[12,13]}$

Results from three hospitals in the Capital Region of Denmark showed that the older medical patient account for nearly half of all acute admissions and around 39\% of them are discharged within 24 hours. ${ }^{[14]}$ Acutely admitted older medical patients $(+65$ years) are characterized by one or more of the following: acute severe illness, co-morbidity, polypharmacy, cognitive impairments, functional disabilities, and need for home care. ${ }^{[15]}$ Nurses in acute care settings play a key role in identifying problems and targeting interventions to prevent a decline in functional ability and to maintain self-care capacity. ${ }^{[16]}$ The often short length of stay and the complexities of this patient group make documentation crucial in order to pass on important knowledge in the health care system. According to national Danish guidelines, nursing documentation should contain core areas such as: nutritional status, pain, sleep, urinary- and bowel elimination, skin and tissue, cognitive and psychosocial factors. ${ }^{[17]}$ In general, studies which have investigated congruence between patient records and patient-reported symptoms conclude a low agreement. ${ }^{[18,19]}$ Studies on nursing documentation in elderly patients have been focused upon structured documentation of: functional ability, ${ }^{[20]}$ nutrition, ${ }^{[21]}$ pressure ulcers, ${ }^{[22,23]}$ delirium, ${ }^{[7]}$ and dementia. ${ }^{[24]}$ In Denmark, nursing reports contain the possibility to document both structured and unstructured, such as free text notes. Though, to the best of our knowledge, the documentation practice and its association to patient impairments have not been examined as a comprehensive, combined set of nursing core areas. By only investigating

Published by Sciedu Press one or few areas at a certain time point, we could risk that the core area studied was not the most central for the patient in the acute setting.

The aims of this study were therefore; firstly to examine the levels of structured and unstructured nursing documentation practice of eight nursing core areas. And secondly, to examine the association between the documentation levels and patient reported impairments, age, sex, morbidities, and self-rated health of acutely admitted older medical patient within those specific areas.

\section{METHODS}

\subsection{Setting}

In Denmark, the public funded health care system covers all primary and specialist services uniformly for all citizens independent of the individual's income and insurance. The study took place in the Medical Department at a large Danish University Hospital. The department consisted of seven medical specialties: acute medical ward, cardiology, respiratory medicine, geriatrics, endocrinology, infectious diseases, and gastroenterology.

\subsection{Design and procedure}

The study was a prospective cross sectional observational study. The study was part of a larger cohort study conducted at a medical department from December 2010 to May 2012. Previous studies on the cohort have been published elsewhere. ${ }^{[25-27]}$ As this cohort also have been used to investigate mobility and function under and after hospitalization the inclusion criteria were: $\geq 65$ years, acutely admitted from their own home, and diagnosed with one or more co-morbidities beside their acute diagnose leading to the hospitalization. Exclusion criteria were: unable to cooperate, unable to speak Danish, inability to walk, isolation due to infectious diseases, patients with chronic obstructive pulmonary disease (COPD) enrolled in a rehabilitation program, transfer to the Intensive Care Unit, expected hospital stay $<48$ hours, and terminal illness. A daily list of newly admitted patients was screened every day during inclusion period, from Monday to Friday. Eligible patients were approached by researchers on the day of their admission and structured interviews were performed within 24 hours of admission by researchers. After discharge, an audit of nursing records from the entire hospitalization was carried out by the researchers.

\subsection{Structured interview}

The patients $(n=90)$ underwent a structured interview at admission and were subsequently categorized into: (1) Impaired, (2) Non-impaired. The patients only had to be impaired in one of the eight core areas to count as impaired in 
that specific category. Patients were considered impaired if they had low appetite ("Do you experience low appetite?"), had experienced weight loss within the last three months ("Have you lost weight during the last three months?"), had any sleeping problems ("Do you experience sleeping problems?"), suffered from habitual urinary incontinence ("Do you suffer from habitual urinary incontinence?"), if the patient had any pressure ulcers ("Do you suffer from pressure ulcers?"), or had any pain (“Are you in pain now?"). Pain was scored on a 5-point Verbal Rating Scale, ${ }^{[28]}$ however, in this study we only use the result of the first question. Cognitive impairment was assessed with the MMSE which is a validated tool for assessing cognitive function. The MMSE consists of 13 items with a total score of 0 to 30 . Cognitive impairment was defined as a score $\leq 24 .{ }^{[29]}$ Depression was assessed with the GDS-5, which is a shorter version of the original scale GDS-30, ${ }^{[30]}$ with only five items. Impairment regarding depression was defined as a score of 2 or above. Finally, self-rated health was measured by EQ VAS rating scale, ${ }^{[31]}$ a visual Analogue Scale (VAS) with numeric values from $0-100$, where 0 is "worst imaginable health state" and 100 is "best imaginable health state".

\subsection{Audit of nursing records}

The documentation practice at the hospital is twofold. Medical doctors, physiotherapists, and occupational therapists document in the main medical record, whereas nurses document in the nursing records. We selected eight nursing core areas to determine documentation practice in handwritten nursing records, based on core areas included in previous studies $^{[32,33]}$ and available variables in the cohort. Appetite and weight loss should be noted in the Nutritional Risk Screening instrument (NRS 2002), ${ }^{[34]}$ which is mandatory when hospitalized in Denmark. Sleeping and urinary incontinence counted as documented, even if it was only described as "i.a." (short for "nothing abnormal" in Danish), or solely for sleep: "slept during oversight" which is a standard phrase used in nursing records. Screening for pressure ulcer is mandatory; therefore the screening tool for pressure ulcers ${ }^{[35]}$ had to be filled out to count as documented. Pain should be written as a VAS-score, since this is the agreed measure for pain at the examined hospital. However, we also examined if the words "pain" or "ache" were written in unstructured notes. Cognitive screening with the Mini-Mental State Examination (MMSE) ${ }^{[29]}$ and depression screening with the Geriatric Depression Scale (GDS-5) ${ }^{[36]}$ had to be filled out to count as documented. Both MMSE and GDS are not mandatory, therefore unstructured notes concerning the unstructured documentation of cognitive level and depression were also examined. We used the most common words or phrases in the Danish nursing records and looked for those in records from the studied hospitalization. Since more researchers investigated the same records all findings were validated. Cognitive level was considered documented if the following words were used in the nursing record: "confused", "demented", "muddled", "clearheaded", "lucid" or "VKO". VKO is in Danish short for "Awake, lucid and oriented" in time and place. Depression was considered documented if the following word was used in the nursing record: "depressed". From the hospital register, we collected information on comorbidities and calculated the Charlson Comorbidity Index (CCI) score ${ }^{[37]}$ using International Classification of Diseases, ICD-10 codes, from the current hospitalization. The CCI was used as an indicator of comorbid conditions at admission and categorized as 0 and $\geq 1$.

\subsection{Statistical methods}

To calculate power for this study we used the Likelihood Ratio Chi-square Test for Two Proportions. We used a sample of 90 persons with 45 persons in each group, and a significance level of 0.05 . We then expected to find a prevalence of documentation of 0.40 in the group, who did not have any impairments and a prevalence of 0.70 in the group, who did have impairments. Given these assumptions we calculated power of 0.82 . We tested whether documentation practice was associated with impairment status using the chi-squared test. In analysis where one or more of the expected counts were less than five, we used the Fisher's Exact Test. Data are presented as numbers and percentages or as medians with a corresponding interquartile range (IQR). The level of significance was set at 0.05 , and all statistical tests were two-tailed and based on the hypothesis that patients who are impaired in a given core area are more likely to have documentation in that particular core area. The statistical analyses were performed using SAS ${ }^{\circledR} 9.3$ for Windows.

\subsection{Ethics}

The local Research Ethics Committee for The Capital Region approved the study (06072010-1631). All participants received both written and oral information about the project, voluntary participation, and confidentiality. All procedures were conducted in accordance with the Declaration of Helsinki. ${ }^{[38]}$ The researchers were not employed in the participating wards.

\section{RESULTS}

Overall, 2,245 patients ( $\geq 65$ years) were admitted during the inclusion period to the Medical Section of the Emergency Department (ED). Out of those, 204 eligible patients were asked if they were interested in participating. Of these patients, 90 patients granted approval to participate and completed the interview. The study population consisted of an 
equal amount of men and women with a median age of 82 years. The characteristics of the patients are depicted in Table 1. Interviews showed that for instance $51 \%$ of the patients had reported weight loss within the last 3 months, $43 \%$ had sleeping problems, and 39\% showed depressive symptoms using the GDS-5.

Table 1. Characteristics of the study population

\begin{tabular}{lll}
\hline Background data & Total N & \% \\
\hline Women & 90 & 50 \\
Age (median [IQR]) & 90 & $82(76 ; 86)$ \\
Charlson-index score & 89 & \\
$\quad 0$ & & 54 \\
$\quad \geq 1$ & 79 & 46 \\
EQ-VAS (median [IQR]) & $50(40 ; 65)$ \\
\hline Eight patient-reported areas of study & \\
\hline Low appetite & 88 & 53 \\
Weight loss within last 3 months & 88 & 51 \\
Sleeping problems & 87 & 43 \\
Urine incontinence & 90 & 40 \\
Pain & 90 & 33 \\
Pressure ulcer & 89 & 5 \\
Cognitive impairment, MMSE $\leq 24$ & 83 & 27 \\
Depressive symptoms, GDS-5 $\geq 2$ & 88 & 39 \\
\hline
\end{tabular}

Note. IQR: Interquartile range; EQ-VAS: Self rated health from 0-100; MMSE: Mini-Mental State Examination; GDS-5: Geriatric Depression Scale

\subsection{Documentation practice}

In Figure 1, documentation practice within the eight core areas are displayed. The highest levels show that $80 \%$ of the patients had appetite documented, $62 \%$ had weight loss within three months documented, $63 \%$ had sleep documented, and $50 \%$ had documented if they suffered from urine incontinence. Lower levels show that $29 \%$ of the patients had documented if they were experiencing pain, $33 \%$ were screened for pressure ulcer, $4 \%$ were screened for cognitive impairment, and 5\% were screened for depression. Of the first six core areas, 1 patient $(1 \%)$ had no areas documented, 10 (11\%) had 1 area documented, 20 (22\%) had 2 areas, 21 (23\%) had 3 areas, 21 (23\%) had 4 areas, 13 (14\%) had 5 areas and $4(4 \%)$ had all 6 areas documented. Core area 7 and 8 are not required to be made by nurses, and are therefore not counted for. When examining the unstructured notes in the nursing records we found that $99 \%$ of the patients had pain documented. Wordings like "no pain" or "very affected by pain" were counted for, as they showed that nurses had considered their situation. Presumably, due to the Danish standard phrase "VKO", meaning "awake, lucid and oriented" $97 \%$ had their cognitive level documented, and $23 \%$ had depression documented.

Published by Sciedu Press

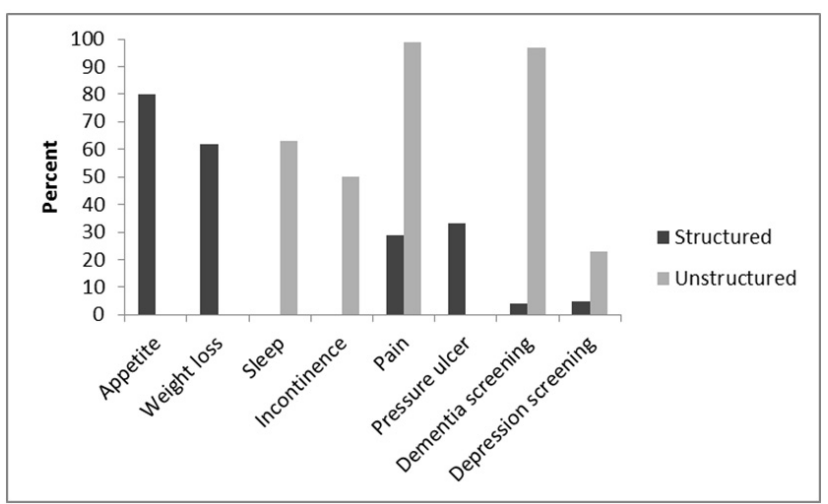

Figure 1. Documentation prevalence covering eight core areas

\subsection{Documentation practice related to patient reported impairments}

To investigate whether patients with reported impairments within the eight core areas had a higher degree of documentation, we tested associations between documentation practice for both patients with and without reported impairments in a given core area, which is shown in Figure $2.87 \%$ of the patients who had impairments regarding appetite had the NRS 2002 documented, and 74\% of those not having impairments had the NRS 2002 documented $(p=.10)$. The pattern was similar for weight loss $(69 \%$ vs. $58 \%, p=.30)$, sleep $(65 \%$ vs. $64 \%, p=.93)$, urine incontinence $(53 \%$ vs. $48 \%$, $p=.67)$, pain $(33 \%$ vs. $27 \%, p=.55)$, pressure ulcers $(50 \%$ vs. $33 \%, p=.60)$, cognitive impairment $(10 \%$ vs. $2 \%$, $p=.30$ ), and depression ( $5 \%$ vs. $5 \%, p=1.00$ ). No association was found in any of the eight core areas between impairments and documentation prevalence.

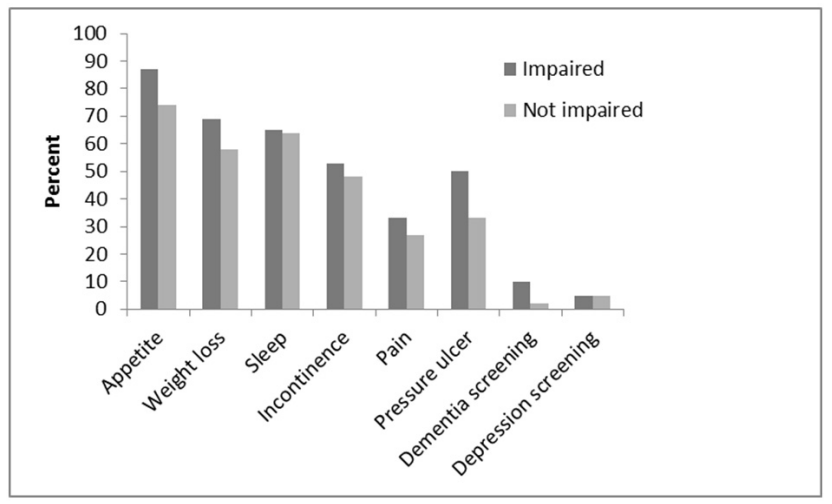

Figure 2. Documentation prevalence for patients with and without impairments within eight core areas of nursing

We investigated whether age, sex, CCI, or self-rated health was associated to documentation levels. For age $p$-values for all eight core areas were $>.13$ and for sex all $p$-values were $>.18$, except for a borderline significant result ( .06) 
regarding sex and documentation of pain. In total, $37.8 \%$ of the women who were in pain had it documented, whereas only $20 \%$ of the men in pain had it documented. Regarding CCI all $p$-values were $>.43$ and for self-rated health $p$-values were $>.15$.

\section{Discussion}

Documentation practice for nutrition was highest, corresponding to $80 \%$. Though, due to the mandatory documentation requirements of the examined core areas, with an ideal of $100 \%$, the general documentation prevalence in this study was considered low. Further, we found no associations between patient impairments and documentation practice. Of the required documentation areas only $4 \%$ had all six areas documented and median patients had three areas documented.

The finding of low documentation practice among nurses is in agreement with previous studies describing documentation as inadequate and inaccurate. ${ }^{[7,23,39]}$ The best documented core area was nutrition, which is mandatory to document when hospitalized in Denmark and is a part of the accreditation process. When examining the unstructured notes in the nursing records for pain, cognitive level, and depression, we found a better documentation practice. In this study the VAS-score for pain was only documented in $23 \%$ of the nursing records, whereas pain was documented in $99 \%$ of the unstructured parts of the nursing records. This unstructured way of documenting may cause challenges in monitoring change over time as it has been demonstrated that the most important components of pain assessment in older adults are regular documentation of pain using standardized tools. ${ }^{[40]}$ Documentation of pain is essential to measure the effect of interventions and is essential to facilitate collaboration among clinicians for the individual patients' pain treatment. Another advantage by the use of pain scales is that they leave less room for interpretation and risk of misunderstandings. The high prevalence of unstructured documentation of cognition could be caused by the inclusion of VKO as a criteria, which was a very commonly used standard phrase in the Danish nursing records, which has not been validated as a clinical measure.

Generally, literature on the separate themes of nursing core areas has shown a low level of documentation. Hypothesizing that the nurses used their clinical intuition and only documented where they judged necessary, we tested if nursing core areas were documented mainly for patients with impairments in the given area. However, we found the same documentation practice for patients with impairments and patients without impairments for all core areas. The missing association between patient impairment and nursing docu- mentation has been observed earlier. ${ }^{[7,8]}$ However, these studies differ in terms of the definition of documentation, as they examined the quality and if the documentation was accurate by studying the content of the documentation. This study broadly examines if documentation in a given area is made at all, looking at both unstructured notes and schemes.

Nursing documentation and the transfer of knowledge between shifts and wards are important for both patients with and without impairments to ensure a coherent hospital stay, that we do not miss important information, and to avoid being asked the same questions several times. However, in this study it did not seem as if the patients' impairments, age, sex, CCI, or self-rated health were influencing factors for documentation practice. Factors such as workload, number of patients per nurse, disrupted work, and time have been found to negatively influence documentation practice. ${ }^{[9-11]}$ On the other hand, other results show that nurses actually spend $35 \%$ of their working time on documentation and less on patient care activities. ${ }^{[41]}$ In the light of our results, it is a substantial amount of time to use on documentation, if what is documented does not correspond to patient reported impairments. In this study, we found a low prevalence of structured documentation practice, but a high prevalence of unstructured documentation practice. This could indicate that the information which one nurse wants to pass on to the next does not fit within the existing structured scheme. Moss et al. have studied free text narrative nursing documentation entered in a structured record utilized in an intensive care unit and found that around $25 \%$ of the free text could have been written in the structured part of the record. The majority of the free text content was summaries of the patient's condition at a certain point in time to condense a vast amount of information to provide colleagues with an overview. ${ }^{[42]}$ This is an interesting aspect to follow in future research, especially since The Capital Region of Denmark is currently implementing a new electronic patient record on all hospitals (EPIC) that requires systematically ticking off boxes and leaves little or no room for unstructured notes. A review suggests that standardized documentation is associated with more positive than negative effects, for example regarding main outcomes as quality and content. ${ }^{[4]}$ Also, documentation has been shown to be important in relation to mortality, as it was found that certain patterns of nursing documentation within electronic health records could be used to predict patient mortality. ${ }^{[43]}$ An ethnographic study carried out in a medical ED found that nurses tended to document screenings supporting a flow culture, where the primary objective for ED nurses were to secure free beds for the next patients. Hence, if the documentation did not maintain patient flow in the department, the chance of nurses documenting was low. ${ }^{[4]}$ It is possible, that 
flow culture could have an influence on the low documentation prevalence in our study, although we studied the entire hospitalization and thereby other wards as well, where there can be other contributing factors to documentation levels. We find that, the lack of association between impairments and prevalence of documentation could be caused by; either that other factors than clinical intuition determines whether impairment is documented, or that clinical intuition may not be sufficiently accurate for patients with self-reported impairments. Still, the consequence of this lack in documentation is the risk of missing potential problems and thereby not providing relevant care actions, potentially influencing patient safety. A recent study showed that documentation errors had the strongest effect on measured patient safety outcomes, including adverse events due to missing or inaccurate data. ${ }^{[45]}$ This supports that there is a continuous need to debate what needs to be documented, when and how.

\section{Strengths and limitations}

The strength of our study was the comprehensive and systematic investigation of patient impairments, which made it possible to validate the nurses' documentation. Also, we pooled data from different wards and looked across an entire trajectory, which added strength to our results. The limitations of this study were the small sample size and that results from the interviews show a one-point prevalence that can change over time during a patient trajectory. Since this study is part of a larger cohort study, the in- and exclusion criteria influenced the selection of patients. Therefore, we do not have the frailest patients included, since they had to be home-living and able to walk. Also, the investigations were based on interviews with patients and it is known that self-reports can have limitations. Furthermore, the results do not necessarily reflect the actual care given to the patients.

\section{Conclusions}

In general, we found low documentation prevalence in the nursing records of acutely admitted older home-living patients. The prevalence for documentation of appetite was highest. For all the eight core nursing areas we found no difference in the prevalence of documentation for patients with impairment compared to patients without impairment. The results imply that something else than national guidelines, patient impairments, age, sex, CCI, and self-rated health of the patient are determining whether documentation is done or not.

\section{ACKNOWLEDgements}

Authors would like to thank patients and staff in the participating wards. In addition, thanks to members of the Optimed research group for contributing with their professional expertise and useful feedback.

\section{FUNDING}

This study did not receive any specific funding. The research group Optimed operates under a grant from the Danish Ministry of Health (Grant number 9170). The funding source had no role in the design or execution of this study.

\section{CONFLicts OF INTEREST Disclosure}

The authors declare they have no conflicts of interest.

\section{REFERENCES}

[1] Friesen MA, White SV, Byers JF. Handoffs: implications for nurses. 2008. Available from: https://www.ncbi.nlm.nih.gov/books /n/nursehb/ch34/?report=reader

[2] Kripalani S, LeFevre F, Phillips CO, et al. Deficits in communication and information transfer between hospital-based and primary care physicians. JAMA J Am Med Assoc. 2007; 297(8): 831-841. Available from: http://jama.ama-assn.org/content/297/8/831. short

[3] Urquhart C, Currell R, Grant MJ, et al. Nursing record systems: effects on nursing practice and healthcare outcomes. Cochrane Database Syst Rev. 2009; 1: CD002099. https://doi.org/10 .1002/14651858.CD002099.pub2

[4] Saranto K, Kinnunen UM. Evaluating nursing documentation - research designs and methods: systematic review. J Adv Nurs. 2009 Mar; 65(3): 464-76. PMid: 19222644. https://doi.org/10.111 $1 / j .1365-2648.2008 .04914 . x$

[5] Wang N, Hailey D, Yu P. Quality of nursing documentation and approaches to its evaluation: a mixed-method systematic review. J
Adv Nurs. 2011 Sep; 67(9): 1858-75. PMid: 21466578. https: //doi.org/10.1111/j.1365-2648.2011.05634.x

[6] Gogler CJ, Hullin C, Monaghan V, et al. The chaos in primary nursing data: good information reduces risk. Electron J Health Inform. 2009; 5(1): 6. Available from: http://www.ejhi.net/ojs/ind ex.php/ejhi/article/view/102

[7] Voyer P, Cole MG, McCusker J, et al. Accuracy of nurse documentation of delirium symptoms in medical charts. Int J Nurs Pract. 2008; 14(2): 165-177. PMid: 18315830. https://doi.org/10.1111/j. 1440-172X.2008.00681.x

[8] Gunningberg L, Ehrenberg A. Accuracy and quality in the nursing documentation of pressure ulcers: a comparison of record content and patient examination. J Wound Ostomy Cont Nurs Off Publ Wound Ostomy Cont Nurses Soc WOCN. 2004 Dec; 31(6): 328-35. https://doi.org/10.1097/00152192-200411000-00004

[9] Paans W, Nieweg RM, van der Schans CP, et al. What factors influence the prevalence and accuracy of nursing diagnoses documentation in clinical practice? A systematic literature review. J Clin Nurs. 2011 Sep; 20(17-18): 2386-403. PMid: 21676043. 
https://doi.org/10.1111/j.1365-2702.2010.03573.x

[10] Cheevakasemsook A, Chapman Y, Francis K, et al. The study of nursing documentation complexities. Int J Nurs Pract. 2006 Dec; 12(6): 366-74. PMid: 17176310. https://doi.org/10.1111/j. 1440-172X . 2006.00596. $\mathrm{x}$

[11] Blair W, Smith B. Nursing documentation: frameworks and barriers. Contemp Nurse. 2012 Jun; 41(2): 160-8. PMid: 22800381. https://doi.org/10.5172/conu.2012.41.2.160

[12] Høgsbro K. Evidensbaseret praksis- forhaabninger, begraensninger og muligheder (Evidence based practices - Expectations, limitations and possibilities). Tidsskr Forsk Sygd Og Samf. 2011; 8(15). Available from: http://ojs.statsbiblioteket.dk/index.ph $\mathrm{p} /$ sygdomogsamfund/article/view/5737

[13] Trydegård GB. Care work in changing welfare states: Nordic care workers' experiences. Eur J Ageing. 2012 Jun; 9(2): 119-29. PMid: 28804413. https://doi.org/10.1007/s10433-012-0219-7

[14] Hermansen S, Ellekilde GE, Rytter L, et al. Analyse af medicinske korttidsindlaeggelser af aeldre patienter med fokus paa alternative losninger (Analysis of medical short term hospitalizations of older patients focusing on alternative solutions). Ugeskr Laeger. 2015; 177: V10140554. PMid: 25749287. Available from: https://www.re searchgate.net/profile/Lars_Rytter/publication/273 324832_Analysis_of_medical_short-term_admissions_o f_elderly_patients_with_focus_on_alternatives_to_h ospitalization/links/55b4b32508ae9289a0898901.pdf

[15] National Board of Health. Styrket indsats for den ældre medicinske patient: fagligt oplæg til en national handlingsplan (Additional efforts for the older medical patient. Professional guideline for a national strategy). Copenhagen, Denmark: National Board of Health; 2011. Available from: http://www.sst.dk/ /media/A6D89E8B22C9 4177BE440B734FC36E53. ashx

[16] Boltz M, Resnick B, Capezuti E, et al. Functional decline in hospitalized older adults: can nursing make a difference? Geriatr Nur (Lond). 2012; 33(4): 272-279. Available from: http://www.sciencedir ect.com/science/article/pii/S0197457212000675

[17] Danish Ministry of Health and Prevention. Guidance for nursing records. (Vejledning om sygeplejefaglige optegnelser VEJ nr 9019 af 15/01/2013). 2013. Available from: https ://www.retsinformat ion. dk/pdfPrint . aspx?id=144979

[18] Corser W, Sikorskii A, Olomu A, et al. Concordance between comorbidity data from patient self-report interviews and medical record documentation. BMC Health Serv Res. 2008; 8: 85. PMid: 18416841. https ://doi.org/10.1186/1472-6963-8-85

[19] Pakhomov SV, Jacobsen SJ, Chute CG, et al. Agreement between patient-reported symptoms and their documentation in the medical record. Am J Manag Care. 2008 Aug; 14(8): 530-9. PMid: 18690769

[20] Jensdóttir AB, Jónsson P, Noro A, et al. Comparison of nurses' and physicians' documentation of functional abilities of older patients in acute care - patient records compared with standardized assessment. Scand J Caring Sci. 2008; 22(3): 341-347. PMid: 18840217. https://doi.org/10.1111/j.1471-6712.2007.00534.x

[21] Halvorsen K, Eide HK, Sortland K, et al. Documentation and communication of nutritional care for elderly hospitalized patients: perspectives of nurses and undergraduate nurses in hospitals and nursing homes. BMC Nurs. 2016 Dec; 15: 70. PMid: 27980452. https ://doi.org/10.1186/s12912-016-0193-z

[22] Dahlstrom M, Best T, Baker C, et al. Improving identification and documentation of pressure ulcers at an urban academic hospital. Jt Comm J Qual Patient Saf Jt Comm Resour. 2011 Mar; 37(3): 123-30. https ://doi.org/10.1016/S1553-7250(11)37015-8

[23] Hansen RL, Fossum M. Nursing documentation of pressure ulcers in nursing homes: comparison of record content and patient ex- aminations. Nurs Open. 2016 Jul; 3(3): 159-67. Available from: http://doi.wiley.com/10.1002/nop2.47

[24] Kihlgren A, Wimo A, Mamhidir AG. Older patients referred by community nurses to emergency departments - a descriptive crosssectional follow-up study in a Swedish context. Scand J Caring Sci. 2014 Mar; 28(1): 97-103. PMid: 23581579. https ://doi.org/10 $.1111 /$ scs .12044

[25] Pedersen MM, Bodilsen AC, Petersen J, et al. Twenty-Four-Hour Mobility During Acute Hospitalization in Older Medical Patients. J Gerontol A Biol Sci Med Sci. 2012 Sep 12.

[26] Bodilsen AC, Pedersen MM, Petersen J, et al. Acute hospitalization of the older patient: changes in muscle strength and functional performance during hospitalization and 30 days after discharge. Am J Phys Med Rehabil Assoc Acad Physiatr. 2013 Sep; 92(9): 78996. PMid: 23552331. https ://doi.org/10.1097/PHM. Ob013e $31828 c d 2 b 6$

[27] Lawson-Smith L, Petersen J, Jensen PS, et al. Nutritional Risk in Acutely Admitted Older Medical Patients. Am J Food Nutr. 2015; 3(3): 84-89.

[28] Closs SJ, Barr B, Briggs M, et al. A comparison of five pain assessment scales for nursing home residents with varying degrees of cognitive impairment. J Pain Symptom Manage. 2004 Mar; 27(3): 196-205. PMid: 15010098. https://doi.org/10.1016/j.jpai nsymman. 2003.12.010

[29] Folstein MF, Folstein SE, McHugh PR. "Mini-mental state": A practical method for grading the cognitive state of patients for the clinician. J Psychiatr Res. 1975 Nov; 12(3): 189-98. https: //doi.org/10.1016/0022-3956 (75)90026-6

[30] Yesavage JA, Brink TL, Rose TL, et al. Development and validation of a geriatric depression screening scale: a preliminary report. J Psychiatr Res. 1982; 17(1): 37-49. https://doi.org/10.1016/00 22-3956 (82) 90033-4

[31] Brooks R. EuroQol: the current state of play. Health Policy. 1996; 37(1): 53-72. https://doi.org/10.1016/0168-8510(96) 008 22-6

[32] Adamsen L, Tewes M. Discrepancy between patients' perspectives, staff's documentation and reflections on basic nursing care. Scand J Caring Sci. 2000; 14(2): 120-9. PMid: 12035275. https : //doi.org/10.1111/j.1471-6712.2000.tb00572.x

[33] Ehrenberg A, Ehnfors M. The accuracy of patient records in Swedish nursing homes: congruence of record content and nurses' and patients' descriptions. Scand J Caring Sci. 2001; 15(4): 303-10. PMid: 12453171. https://doi.org/10.1046/j.1471-6712.2001.0 $0044 . \mathrm{x}$

[34] Kondrup J. ESPEN Guidelines for Nutrition Screening 2002. Clin Nutr. 2003 Aug; 22(4): 415-21. https://doi.org/10.1016/S0 261-5614(03) 00098-0

[35] Bergstrom N, Braden BJ, Laguzza A, et al. The Braden Scale for Predicting Pressure Sore Risk. Nursing Research. 1987; 36(4): 205. PMid: 3299278. https : //doi .org/10.1097/00006199-19870 7000-00002

[36] Hoyl MT, Alessi CA, Harker JO, et al. Development and testing of a five-item version of the Geriatric Depression Scale. J Am Geriatr Soc. 1999 Jul; 47(7): 873-8. PMid: 10404935. https : //doi.org/10.1111/j.1532-5415.1999.tb03848.x

[37] Charlson ME, Pompei P, Ales KL, et al. A new method of classifying prognostic comorbidity in longitudinal studies: development and validation. J Chronic Dis. 1987; 40(5): 373-83. https : //doi.org/10.1016/0021-9681(87)90171-8

[38] WHO. World Medical Associacion Declaration of Helsinki. Ethical Principles for Medical Research Involving Human Subjects. Bul- 
letin of the World Health Organization. 2001; 79(4): 373-4. PMid: 11357217.

[39] Li D. The relationship among pressure ulcer risk factors, incidence and nursing documentation in hospital-acquired pressure ulcer patients in intensive care units. J Clin Nurs. 2016 Aug; 25(15-16): 233647. PMid: 27302084 . https://doi .org/10.1111/jocn. 13363

[40] Horgas AL. Pain management in elderly adults. J Infus Nurs Off Publ Infus Nurses Soc. 2003 Jun; 26(3): 161-5. https://doi .org/10 .1097/00129804-200305000-00007

[41] Hendrich A, Chow M, Skierczynski BA, et al. A 36-hospital time and motion study: How do medical-surgical nurses spend their time? RCHE Publ. 2008; 50. Available from: http://docs.lib.purdue.edu/cgi/viewcontent.cgi?ar ticle $=1060 \&$ context $=r c h e \_r p$

[42] Moss J, Andison M, Sobko H. An analysis of narrative nursing documentation in an otherwise structured intensive care clinical infor- mation system. AMIA Annu Symp Proc AMIA Symp AMIA Symp. 2007; 2007: 543-547. PMid: 18693895.

[43] Collins SA, Cato K, Albers D, et al. Relationship Between Nursing Documentation and Patients' Mortality. Am J Crit Care. 2013 Jul 1; 22(4): 306-13. PMid: 23817819. https://doi.org/10.4037/aj cc2013426

[44] Kirk JW, Nilsen P. The influence of flow culture on nurses' use of research in emergency care: An ethnographic study. Klin Sygepleje. 2015; 29(02). Available from: http://www.idunn.no/ts/klin isk_sygepleje/2015/02/the_influence_of_flow_cultur e_on_nurses_use_of_research_in

[45] Jylhä V, Mikkonen S, Saranto K, et al. The Impact of Information Culture on Patient Safety Outcomes: Development of a Structural Equation Model. Methods Inf Med. 2017; 56(Open): e30-8. Available from: http://www.schattauer.de/index.php?id=1214\&doi $=10.3414 / \mathrm{ME} 16-01-0075$ 